Conflicts of interest: There is no conflict of interest.

Vipin Kumar Goel ${ }^{1}$, Hetal Kumar Vadera ${ }^{2}$, Tuhin Mistry $^{3}$

${ }^{1}$ Consultant, Department of Anaesthesiology, Ganga Medical Centre Hospitals Pvt Ltd, Coimbatore, (India) ${ }^{2}$ Consultant Anaesthesiologist, Sterling
Hospital, Rajkot, Gujarat, (India) 35enior Resident, Onco Anaesthesiology Pain and Palliative Care, Dr B. R. Ambedkar Institute Rotary Cancer Hospital, All India Institute of Medical Sciences, New Delhi, (India)

Correspondence: Dr Tuhin Mistry dr.tuhin2014@gmail. com; Mobile: 918240823526

\title{
REFERENCES
}

1. Melvin JP, Schrot RJ, Chu GM, Chin KJ. Low thoracic erector spinae plane block for perioperative analgesia in lumbosacral spine surgery: a case series. Can $J$ Anaesth. 2018;65(9):1057-65. [PubMed] DOI: 10.1007/s12630-018-1145-8.

2. Vadera HK, Mistry T. Erector spinae plane block: Anatomical landmarkguided technique. Saudi J Anaesth 2019;13:268-9 [PubMed] [Free Full Text] D0I:10.4103/sja.SJA $780 \quad 18$
3. Tsui BCH, Fonseca A, Munshey F, McFadyen G, Caruso TJ. The erector spinae plane (ESP) block: A pooled review of 242 cases. J Clin Anesth. 2018;53:29-34. [PubMed] DOI: 10.1016/j.jclinane.2018.09.036

\section{An alternative approach for continuous monitoring of heart and breath sounds in pediatric patients}

\begin{abstract}
Citation: Kumar D, Ali S, Khan FA, Suleman M. An alternative approach for continuous monitoring of heart and breath sounds in
\end{abstract} pediatric patients. Anaesth pain \& intensive care 2019;23(4):405-406. DOI: 10.35975/apic.v23i4.1180

Anesthetic management in neonates, infants and young children is always a challenge. Both esophageal and precordial stethoscopes are used for continuous monitoring of heart and breath sounds in this age group. ${ }^{1}$ Recent (2018) publication of Standards for Safe Practice of Anesthesia by World Health Organization-World Federation of Societies of Anesthesiologists (WHO-WFSA) have also recommended monitoring with a precordial or esophageal stethoscope. ${ }^{2}$ By using an esophageal stethoscope both heart and breath sounds can be continuously monitored and any obstruction of endotracheal tube (ETT) can be readily detected. However, the detection of one lung ventilation due to incidental endobronchial ETT placement during surgical positioning and tissue handling may be difficult. Complications of esophageal stethoscope placement have been reported e.g. incidental tracheal and bronchial insertion resulting in hypoxia, hoarseness, oropharyngeal trauma or bleeding. ${ }^{3}$

Precordial stethoscope on the other hand is a relatively safe, non-invasive and inexpensive alternative to esophageal stethoscope. It is usually fixed on the chest wall to the left of lower part of sternum in order to auscultate both the heart and breath sounds. However, it's applicability is limited since it is easily displaced and its contact with the skin may require frequent refixing during surgery interfering with sterility. The current practice for the fixation of precordial stethoscope varies among anesthesiologists as there is no standard recommendation.

We have used Self Adhesive Fabric Tape (Mefix) in our

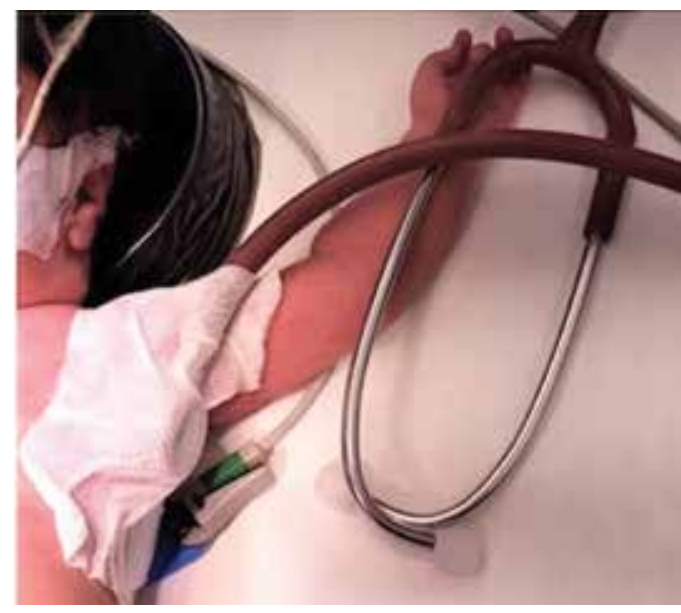

Figure-I: Shows stethoscope and Mefix $10 \times 10$ fixed in $5^{\text {th }}$ intercostal space for lower abdominal surgery and in the left axilla for contralateral thoracic surgery. 
pediatric patients for the fixation of precordial stethoscope as shown in Figure 1. We suggest the following approach to fix the precordial stethoscope. Hold stethoscope on a site at which heart and breath sound are loudly audible and apply one piece of Mefix of $10 \times 10 \mathrm{~cm}$ to secure the stethoscope. Mefix fixes the edges of precordial stethoscope precisely and ensures firm contact with the patient's skin. The usual position for the stethoscope is the 5th intercostal space (Figure 1) medial to the left nipple however, position can be changed according to the nature of surgery and clear audibility of heart and breath sounds. Mefix is gentle to the skin and it is relatively cheap and usually readily available in the operating rooms.
Dileep Kumar, FCPS, Summaiya Ali, FCPS, Fauzia Anis Khan, FCPS, FRCA, MuhammadSuleman, FCPS

Department of Anesthesia, The Aga Khan University, Stadium Road, P. O. Box 3500, Karachi, (Pakistan)

Correspondence: Dr Dileep Kumar, FCPS, Assistant Professor,

The Aga Khan University, Stadium Road, P. O. Box 3500, Karachi, (Pakistan)

Email: dileep.kumar@aku.edu; dkhiloi@gmail.com

Received: 30 December 2019;

Reviewed \& Accepted: 31 December 2019

\section{REFERENCES}

1. Watson A, Virsam A. Survey of the use of oesophageal and precordial stethoscopes in current paediatric anaesthetic practice. Paediatr Anesth 2001;11:437-442. [PubMed] DOI: 10.1046/.1.1460-9592.2001.00698.x

2. Gelb AW, Morriss WW, Johnson W,
Merry AF. World Health OrganizationWorld Federation of Societies of Anaesthesiologists (WHO-WFSA) International Standards for a Safe Practice of Anesthesia. Can J Anaesth 2018;65(6):698-708. [PubMed] DOI: $\underline{10.1007 / \mathrm{s} 12630-018-1111-5}$
3. Cho K, Kim M, Lee W, Lee JH, Lim $\mathrm{SH}$, Lee KM, et al. The oropharyngeal bleeding after esophageal stethoscope insertion -A Case Report. Anesth Pain Med 2016;11:104-108. [Free full text] DOI: $10.17085 / a p m .2016 .11 .1 .104$ 